\title{
E-learning: Mengembangkan kemampuan membuat Teks Prosedur
}

\author{
Michelle Devina Pasaribu \\ E-mail: michelle.devina6122@student.unri.ac.id \\ Program Studi Pendidikan Bahasa dan Sastra Indonesia, Universitas Riau
}

\section{Pengantar}

Saat ini, merupakan era digitalisasi dimana media pembelajaran dapat dilakukan secara online. Khususnya pada saat pandemi yang sedang melanda di Indonesia. Sistem pembelajaran yang awalnya dilakukan secara tatap muka akhirnya dilakukan secara online. Untuk itu, karena belum terbiasa memanfaatkan media pembelajaran online secara penuh banyak sekali siswa yang belum mengerti beberapa materi terutama materi teks prosedur.

Teks prosedur ialah sebuah tulisan yang menunjukkan suatu langkah yang harus diikuti untuk melakukan suatu pekerjaan tertentu. Teks prosedur sendiri memiliki manfaat dikarenakan dapat membantu kita dalam mengetahui cara untuk melakukan aktifitas dan kebiasaan hidup yang benar. Oleh karena itu, pentingnya peserta didik untuk bisa memahami cara penulisan teks prosedur yang baik dan benar agar tidak terjadi kesalahan dalam pembuatan teks prosedur.

\section{Tindakan yang Dilakukan}

\section{a. Memahami Jenis Teks Prosedur}

b. Memahami Kaidah Penulisan Dalam Teks Prosedur

c. Memahami Struktur Teks Prosedur

\section{d. Membuat Teks Prosedur}

Ada beberapa pengertian mengenai teks prosedur. Teks Prosedur adalah teks yang menjelaskan rangkaian tugas-tugas yang saling berhubungan yang merupakan urutan-urutan menurut waktu dan tata cara tertentu untuk melaksanakan suatu pekerjaan yang dilaksanakan berulang-ulang (Ismail Masya, 1994). Ada juga yang mengatakan teks prosedur adalah teks yang menjelaskan urutan kegiatan klerikal, biasanya melibatkan beberapa orang dalam satu departemen atau lebih, yang dibuat untuk menjamin penanganan secara seragam transaksi perusahaan yang 
terjadi berulang-ulang (Mulyadi, 2001). Dari keterangan tersebut dapat kita simpulkan bahwa Teks prosedur ialah sebuah karya sastra yang menunjukkan suatu langkah yang harus diikuti untuk melakukan suatu pekerjaan tertentu.

Dalam memahami teks teks prosedur, pertama-tama harus memahami 3 macam jenis teks prosedur, yaitu teks prosedur sederhana, teks prosedur kompleks, dan teks prosedur protokol. Selanjutnya, dalam membuat sebuah teks prosedur haruslah menggunakan kaidah kebahasaan yang baik dan benar. Dalam kaidah kebahasaannya sendiri, teks prosedur haruslah memenuhi 6 poin kaidah kebahasaan yaitu:

1. Menggunakan kata kerja imperatif

2. Menggunakan kata teknis

3. Menggunakan konjungsi temporal

4. Menggunakan kalimat persuasif

5. Menjelaskan secara rinci mengenai alat dan bahan yang dipakai

6. Menggunakan verba material dan bahan yang dipakai

Setelah memenuhi 6 poin dari kaidah kebahasaan, ketika ingin membuat teks prosedur haruslah mengikuti struktur yang telah ditetapkan. Dalam teks prosedur sendiri terdapat 4 struktur yang harus dipenuhi yaitu Struktur pengantar/pembuka, struktur material dari teks prosedur itu sendiri, struktur dari tahapan/langkahlangkah yang digunakan pada topik yang diangkat dalam teks prosedur, dan struktur yang terakhir yaitu simpulan/kesimpulan.

Jika sudah mengetahui berbagai hal tersebut dan mengikutinya barulah dapat membuat sebuah teks prosedur dan dapat memenuhi tujuan dari teks prosedur sendiri yaitu untuk menjelaskan dan menjelaskan langkah-langkah untuk mencapai tujuan dan pembaca dapat mengikuti petunjuk.

Namun, untuk menyampaikan hal-hal tersebut akan dilakukan dengan menggunakan media pendukung lainnya seperti sebuah video singkat dari youtube, melakukan mentoring dengan grup aplikasi whatsapp.

\section{Sarana Pendukung}

\section{a. Internet}


b. Video Penjelasan Materi Melalui Youtube

c. Laptop/Gawai

d. Mentor Pembimbing

e. Grup Whatsapp

Berdasarkan data internetworldstats, per-tahun 2021 penggunaan internet di Indonesia telah mencapai 212,35 juta jiwa pada Maret 2021. Dan dengan data tersebut, Indonesia masuk ke peringkat ketiga pengguna internet di Asia.

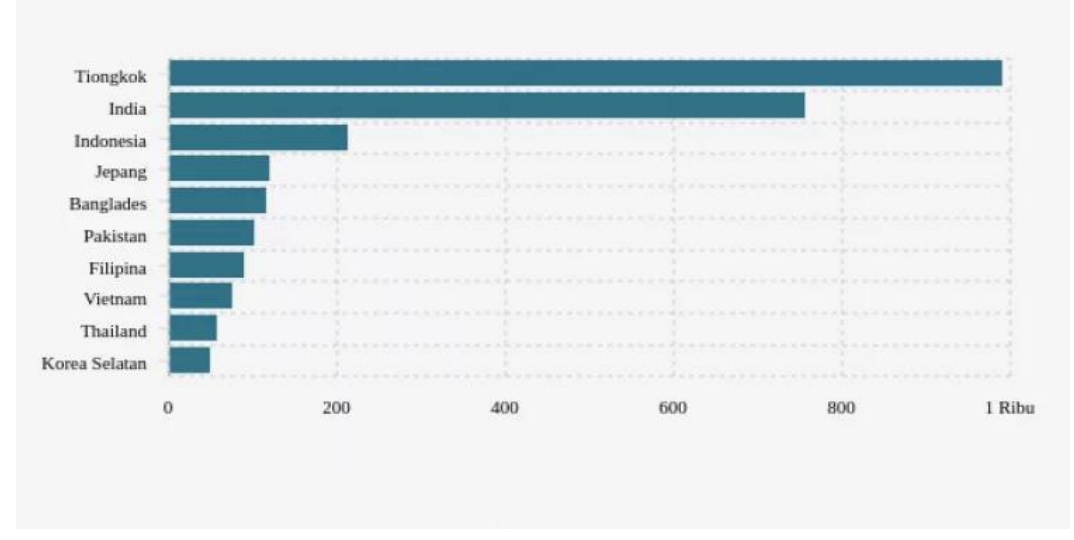

Gambar 1. Grafik Pengguna Internet di Asia

Adanya peningkatan ini tak lain dan tak jauh dari pandemi yang sedang melanda Indonesia sehingga mendorong kegiatan belajar mengajar untuk dilakukan secara daring. Akibatnya, efektivitas pembelajaran beberapa siswa menjadi menurun berdasarkan beberapa jurnal yang saya baca. Hal ini diakibatkan kegagapan orang tua, beberapa peserta didik masih belum mempunyai sarana yang mendukung seperti laptop ataupun gawai untuk melakukan pembelajaran daring.

Kemudian, kurangnya beberapa orang yang paham dan dapat memahami materi itulah mengakibatkan menurunnya efektivitas tersebut. Oleh karena itu, adanya video pembelajaran yang dapat menarik para penonton pada media youtube inilah yang akan membantu berbagai peserta didik dalam memahami materi terutama dalam membuat sebuah teks prosedur. 


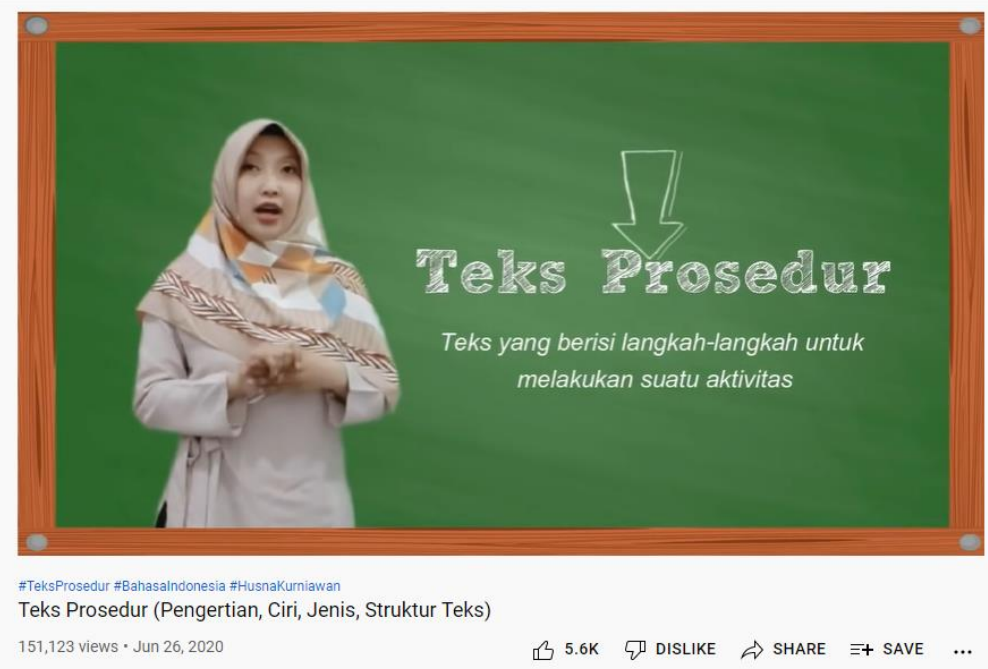

Gambar 2. Contoh Penyampaian Materi Teks Prosedur dari Youtube Selanjutnya, untuk wadah dalam bertanya ketika pembelajaran online dapat dilakukan dengan menggunakan media whatsapp dimana dapat menggunakan fitur grup chatnya yang berisi mentor yang nantinya akan menjelaskan lebih luas lagi tentang materi mengenai teks prosedur tersebut. Dan mentor juga dapat menjelaskan lebih detail berbagai bagian yang sekiranya tidak dipahami oleh peserta didik.

\section{Tindakan Solutif}

a. Menyediakan video resolusi kecil agar dapat diakses peserta didik yang terkendala sinyal

b. Melakukan sesi mentoring melalui grup WA dan menjawab pertanyaan siswa dengan cepat dan tepat

c. Melakukan penyuluhan agar orang tua siswa dapat membimbing para peserta ketika pembelajaran online

d. Memberikan tugas secukupnya agar peserta didik tidak stress

e. Membuat penggalangan dana untuk pengadaan pembelian gawai/laptop bagi peserta didik

f. Membuat video semenarik mungkin agar peserta didik tidak jenuh menontonnya 


\section{Simpulan}

Teks prosedur ialah sebuah tulisan yang menunjukkan suatu langkah yang harus diikuti untuk melakukan suatu pekerjaan tertentu. Dalam membuat sebuah teks prosedur harus memperhatikan 6 poin kaidah kebahasaan dan juga 4 struktur dari sebuah teks prosedur. Dalam pembelajaran daring sendiri terdapat beberapa masalah yang membuat efektivitas kegiatan belajar mengajar menjadi menurun sehingga dalam memahami materi terutama teks prosedur sendiri kemungkinan agak sulit bagi peserta didik.

Dalam melakukan sebuah pemahaman terhadap teks prosedur dapat dilakukan secara unik dan tidak monoton dimana peserta didik dapat melihat materinya dari beberapa video yang telah disediakan di youtube. Kemudian jika peserta didik terdapat masalah dalam memahaminya akan dibantu oleh mentor yang akan siap siaga dalam menanggapi pertanyaan peserta didik.

\section{Referensi}

Halima, \& Wasia, S. (2020). Efektifitas Pembelajaran Daring Pada Masa Pandemi Covid-19 Di SMAN 1 Lambandia. Jurnal Universitas Muhammadiyah Kendari, 4.

Singaraja, S. M. P. N. (2016). Pembelajaran Menulis Teks Prosedur Beradasarkan Hasil Wawancara Di Kelas Viiial. 1-12.

Yulia, I. I. (2018). Pembelajaran menulis teks prosedur kompleks dengan menggunakan metode. Jurnal Pendidikan Bahasa Indonesia, 6(2), 104-122. https://jurnal.unigal.ac.id/index.php/diksatrasia/article/view/176/0

Alam, H. W. N. (2017). Peningkatan Kemampuan Memproduksi Teks Prosedur Kompleks dengan Menggunakan Metode Demonstrasi. Diksatrasia Vol.1 No.1, 1(April), 1-9.

Damayanthi, A. (2020). Efektivitas Pembelajaran Daring di Masa Pandemi Covid 19 pada Perguruan Tinggi Keagamaan Katolik. JURNAL SOSIAL :Jurnal Penelitian Ilmu-Ilmu Sosial, 21(3), 53-56. http://sosial.unmermadiun.ac.id/index.php/sosial/article/view/61 
mpotimes. (2021, October 14). Pengguna Internet Indonesia Peringkat ke-3 Terbanyak di Asia. Retrieved December 4, 2021, from Mpotimes website: https://mpotimes.id/pengguna-internet-indonesia-peringkat-ke-3-terbanyakdi-asia

Viva Budy Kusnandar. (2021, October 14). Pengguna Internet Indonesia Peringkat ke-3 Terbanyak di Asia. Retrieved December 4, 2021, from Katadata.co.id website:

https://databoks.katadata.co.id/datapublish/2021/10/14/pengguna-internetindonesia-peringkat-ke-3-terbanyak-di-asia

Ridwan Karim. (2021, November 16). Pengertian Teks Prosedur: Ciri-Ciri, Jenis, Struktur dan Contoh. Retrieved December 4, 2021, from Buku Deepublish website: https://penerbitbukudeepublish.com/teksprosedur/\#1_Menggunakan_Kata_Kerja_Imperatif

Zakky. (2019, October 16). Pengertian Teks Prosedur|Fungsi, Tujuan, Ciri-Ciri, Kaidah Kebahasaan. Retrieved December 4, 2021, from ZonaReferensi.com website: https://www.zonareferensi.com/pengertian-teks-prosedur/

Husna Kurniawan. (2020). Teks Prosedur (Pengertian, Ciri, Jenis, Struktur Teks) [YouTube Video]. Retrieved from https://www.youtube.com/watch?v=UayGZTwk1Tc

Manurung, N. S. (2020). Kaidah Kebahasaan Teks Prosedur Lengkap - Bahasa Indonesia (PJJ) [YouTube Video]. Retrieved from https://www.youtube.com/watch?v=PERNt9sLZKU

Agustina, R. (2020). Gagasan pembelajaran daring melalui grup whatsapp sebagai kesiagaan menghadapi bencana kabut asap di sma negeri 2 tanah putih rokan hilir. Retrieved December 4, 2021, from Universitas Indonesia Library website: http://lib.ui.ac.id/detail?id=20512716\&lokasi=lokal 


\section{Data Penulis}

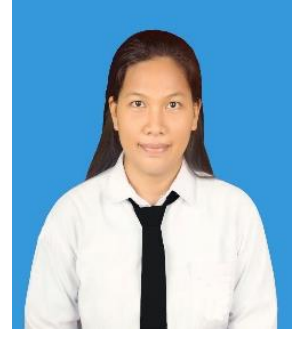

Michelle Devina Pasaribu Penulis lahir di Bandar Lampung, 19 September 2002. Ia merupakan anak kedua dari tiga bersaudara. Penulis berijazah SD Filius Dei Dumai, SMP Santo Tarcisius Dumai dan pada tahun 2020, ia menyelesaikan studi di SMAN 2 Dumai. Saat ini, ia tercatat sebagai mahasiswi Universitas Riau (UNRI) jurusan Pendidikan Bahasa dan Sastra Indonesia melalui jalur Seleksi Mandiri Masuk Perguruan Tinggi Negri Barat ( SMMPTN Barat).

\section{Kontak:}

Hp/WA : 081270192995

Email : michelle.devina6122@student.unri.ac.id 